\title{
EFICIÊNCIA DO INSETICIDA CLORPIRIFÓS NO CONTROLE DE LARVAS DE Diabrotica speciosa (Germ.) (COLEOPTERA: CHRYSOMELIDAE) NA CULTURA DA BATATA
}

\author{
PERFORMANCE OF THE INSECTIDE CHLORPYRIFOS TO CONTROL Diabrotica \\ speciosa (Germ.) (COLEOPTERA:CHRYSOMELIDAE) IN POTATO CROP
}

\author{
Luiz Antonio Salles ${ }^{1}$ Anderson Dionei Grutzmacher ${ }^{2}$
}

RESUMO

Foi avaliado o desempenho do inseticida clorpirifós no controle de larvas de Diabrotica speciosa (Germ.) (Coleoptera:Chrysomelidae), na cultura da batata. $O$ experimento foi desenvolvido na safra de primavera, quando ocorre maior incidência de insetos pragas e, conseqüentemente, danos nos tubérculos de batata no Rio Grande do Sul. As diferentes dosagens e formulações dos inseticidas foram aplicadas no sulco de plantio, utilizando-se clorpirifós (2, 3 e 4 l i.a./ha de Lorsban 480 CE e 2 e $3 \mathrm{~kg}$ i.a./ha de Lorsban $10 \mathrm{G}$ ) e como padrão, forate ( $2 \mathrm{~kg}$ i.a. $/ \mathrm{ha}$ de Granutox 50G). Os melhores controles ocorreram nos tratamentos com Granutox 50G, na dosagem de $2 \mathrm{~kg}$ i.a./ha; seguido por Lorsban $10 \mathrm{G}, 3$ e $2 \mathrm{~kg}$ i.a./ha e Lorsban $480 \mathrm{CE}, 4$ e $3 \mathrm{l}$ i.a./ha

Palavras-chave: Solanum tuberosum, controle químico, pragas de solo.

\section{SUMMARY}

A field trial was conducted to evaluate the performance of the insecticide chlorpyrifos in two formulations, emulsifiable and granular, for the control of Diabrotica speciosa (Germ.) (Coleoptera:Chrysomelidae) in potato. The field trial was conducted during the spring season when incidence of insect pests and, consequently, damage are high in Rio Grande do Sul state, Brazil. The different dosages and formulations of insecticides were applied in the planting furrow utilizing chlorpyrifos $(2,3$ and $4 \mathrm{l}$ i.a./ha of Lorsban $480 \mathrm{CE}$ and 2 and $3 \mathrm{~kg}$ i.a./ha de Lorsban $10 \mathrm{G}$ ) and the standard phorate ( $2 \mathrm{~kg}$ i.a./ha of Granutox $50 G)$. Best field control performances were obtained with Granutox $50 \mathrm{G}$, in the dosage of $2 \mathrm{~kg}$ i.a./ha; Lorsban $10 \mathrm{G}, 3$ and $2 \mathrm{~kg}$ i.a./ha, followed by Lorsban 480 CE, 4 and 3 l i.a./ha.

Key words: Solanum tuberosum, chemical control, soil pests.

\section{INTRODUÇÃO}

A batata é um dos alimentos básicos da população brasileira. A produtividade dessa cultura no Brasil é muito baixa, principalmente se comparada com a dos países europeus, que são produtores tradicionais. A produção brasileira chega ao redor de 2,5 milhões de toneladas e está concentrada nos Estados de Minas Gerais, São Paulo, Paraná, Santa Catarina e Rio Grande do Sul.

No Sul do Brasil, são cultivados anualmente mais de 100.000 ha de batata para o consumo, em dois períodos, março a junho e setembro a dezembro. O Rio Grande do Sul, apesar de ter a maior área plantada, detém a menor produtividade média entre os cinco Estados produtores de batata no Brasil. A área total cultivada em 1995 foi de 48.230ha, com rendimento médio de $9.925 \mathrm{~kg} / \mathrm{ha}$ (FIOREZE $\boldsymbol{e t}$ al., 1998).

Os tubérculos de batata são atacados por diversas espécies de insetos pragas. No Sul do Brasil, as pragas mais comuns são a vaquinha (Diabrotica speciosa, Cerotoma spp.), bicho arame (Heteroderes spp.), lagarta rosca (Agrotis spp.) e coró (Dyscinetus spp., Diloboderus abderus), além dos nematóides causadores de galhas (Meloidogyne spp.). $\mathrm{O}$ ataque destas pragas ocasiona a depreciação comercial do tubérculo e, dependendo da intensidade de danos, até a rejeição para o comércio. As larvas de $\boldsymbol{D}$. speciosa têm causado os danos mais severos (BONINE, 1997). Conseqüentemente, inseticidas

\footnotetext{
${ }^{1}$ Engenheiro Agrônomo, PhD., EMBRAPA-CPACT, CP 403, 96001-970, Pelotas, RS. E-mail: salles@ cpact.embrapa.br. Autor para correspondência.

${ }^{2}$ Engenheiro Agrônomo, Doutor, Professor Adjunto, Departamento de Fitossanidade, FAEM-UFPel., Pelotas, RS. 
para controlar as pragas de solo, incluindo a $\boldsymbol{D}$. speciosa, têm sido cada vez mais usados (SANTOS \& FERNANDES, 1997). As formulações granuladas têm predominado, embora já hajam formulações líquidas que também demonstram boa eficiência de controle (BALCABAO et al., 1997; SANTOS \& FERNANDES, 1997).

O objetivo deste experimento foi verificar a eficácia de diferentes formulações e dosagens de clorpirifós no controle da larva alfinete $\boldsymbol{D}$. speciosa na cultura da batata, aplicadas por ocasião do plantio.

\section{MATERIAL E MÉTODOS}

O experimento foi desenvolvido no período de setembro a dezembro de 1997, em Pelotas, RS. A área onde se desenvolveu o trabalho apresenta solo franco arenoso, boa drenagem e havia sido cultivada com batata por quatro safras, o que favorece a uniformidade e intensidade de infestação de pragas. Foi utilizada a cultivar Trapeira, intensamente atacada pelas larvas de Diabrotica speciosa (BONINE \& SALLES, 1997), plantada de acordo com as técnicas usuais da região (BISOGNIN, 1996). As parcelas experimentais foram constituídas de quatro fileiras com 10 metros lineares, deixandose as duas fileiras externas como bordaduras. O delineamento experimental foi o de blocos ao acaso, com quatro repetições.

Os tratamentos experimentais foram constituídos por várias dosagens e formulações de clorpirifós (2, 3 e 41 i.a./ha de Lorsban 480 CE e 2 e $3 \mathrm{~kg}$ i.a./ha de Lorsban $10 \mathrm{G}$ ) e como padrão forate (2kg i.a./ha de Granutox $50 \mathrm{G}$ ).

Os tratos culturais restringiram-se à capina, amontoa e aplicação de fungicidas na parte aérea. Não foi usada irrigação e nem inseticida na folhagem.

A aplicação dos produtos granulados foi realizada com aplicador AGR-BR. Como material inerte, para aplicação de pequenas quantidades de produto, utilizou-se areia peneirada e seca. A aplicação dos produtos líquidos foi realizada com um pulverizador costal, manual, com pressão constante Jacto, modelo L-20, gastando-se na parcela o equivalente de 400 litros de água por ha. $\mathrm{O}$ adubo (7-11-9, 1500 $\mathrm{kg} / \mathrm{ha}$ ) foi aplicado no sulco, a seguir os tubérculos e, então, o inseticida. Após cada procedimento, foi colocada uma leve camada de solo para evitar o contato direto do adubo e inseticida com a batata semente. O plantio dos tubérculos e a aplicação dos inseticidas foram realizados em 27/10/1997 e a colheita em 23/12/1997.

As avaliações foram procedidas nas duas fileiras centrais da parcela, onde os tubérculos foram colhidos, classificados e, dos que passaram na peneira de $3,5 \times 3,5 \mathrm{~cm}, 100$ foram avaliados quanto ao nível de dano.

Utilizaram-se as seguintes categorias de dano para classificar os tubérculos: $1=$ sem furos; 2 $=1$ a 3 furos; $3=4$ a 7 furos; $4=8$ a 11 furos e $5=$ mais de 11 furos. Somente foram considerados os danos (furos) típicos das larvas de vaquinha $\boldsymbol{D}$. $\boldsymbol{s p e}$ ciosa, desconsiderando-se outros tipos de lesões nos tubérculos.

Os dados obtidos foram submetidos à análise de variância, sendo as médias comparadas pelo teste de Tukey a 5\% de significância.

\section{RESULTADOS E DISCUSSÃO}

A elevada incidência de larvas de Diabrotica speciosa na área experimental pôde ser constatada pela parcela testemunha, onde, aproximadamente, $80 \%$ dos tubérculos apresentaram lesões. Os resultados deste experimento refletem, portanto, o potencial de proteção dos tubérculos de batata, promovidos pelos inseticidas e dosagens testados.

As batatas sem nenhum furo (Categoria de dano 1) foram obtidas em todos os tratamentos, incluindo a testemunha. Nos tratamentos com Lorsban 10G (3kg i.a./ha) e com Granutox 50G ( $2 \mathrm{~kg}$ i.a./ha) obtiveram-se as maiores percentagens de batatas enquadradas nesta categoria, ou seja, $57,5 \%$ e $62,5 \%$, respectivamente (tabela 1 ). Um segundo
Tabela 1 - Percentagem média de tubérculos de batata enquadrados nas categorias de dano de Diabrotica speciosa, Pelotas-RS, 1997.

\begin{tabular}{|c|c|c|c|c|c|c|}
\hline \multirow[b]{2}{*}{ Tratamentos } & \multirow[b]{2}{*}{ Dosagem } & \multicolumn{5}{|c|}{ Categoria de dano ${ }^{1}$} \\
\hline & & 1 & 2 & 3 & 4 & 5 \\
\hline Lorsban $480 \mathrm{CE}$ & 21 i.a/ha & $14,0 c^{2}$ & $36,0 \mathrm{a}$ & $25,0 \mathrm{a}$ & $11,0 \mathrm{a}$ & $14,0 \mathrm{ab}$ \\
\hline Lorsban $480 \mathrm{CE}$ & $31 \mathrm{i} . \mathrm{a} / \mathrm{ha}$ & $32,0 \mathrm{~b}$ & $27,0 \mathrm{a}$ & $20,0 \mathrm{ab}$ & $5,0 \mathrm{a}$ & $16,0 \mathrm{ab}$ \\
\hline Lorsban $480 \mathrm{CE}$ & 4 li.a./ha & $27,5 \mathrm{~b}$ & $33,5 \mathrm{a}$ & $19,0 \mathrm{ab}$ & $10,0 \mathrm{a}$ & $10,0 \mathrm{ab}$ \\
\hline Lorsban $10 \mathrm{G}$ & $2 \mathrm{~kg}$ i.a/ha & $26,0 \mathrm{~b}$ & $38,5 \mathrm{a}$ & $18,0 \mathrm{ab}$ & $7,5 \mathrm{a}$ & $10,0 \mathrm{ab}$ \\
\hline Lorsban $10 \mathrm{G}$ & $3 \mathrm{~kg}$ i.a $/ \mathrm{ha}$ & $57,5 \mathrm{a}$ & 36,0 a & $5,5 \mathrm{~b}$ & $1,0 \mathrm{a}$ & $0,0 \mathrm{~b}$ \\
\hline Granutox $50 \mathrm{G}$ & $2 \mathrm{~kg}$ i.a/ha & $62,5 \mathrm{a}$ & $28,5 \mathrm{a}$ & $8,0 \mathrm{ab}$ & $1,0 \mathrm{a}$ & $0,0 \mathrm{~b}$ \\
\hline Testemunha & - & $22,5 \mathrm{~b}$ & $25,0 \mathrm{a}$ & $23,0 \mathrm{ab}$ & $11,0 \mathrm{a}$ & $18,5 \mathrm{a}$ \\
\hline
\end{tabular}

${ }^{1} 1$ = sem furos; $2=1$ a 3 furos; $3=4$ a 7 furos; $4=8$ a 11 furos e $5=$ com mais de 11 furos por tubérculo.

${ }^{2}$ Médias seguidas pela mesma letra na coluna não diferem estatisticamente entre si pelo teste de Tukey a 5\% de significância. 
grupo de tratamentos, estatisticamente iguais entre si e a testemunha, constitui-se pelo Lorsban $480 \mathrm{CE}$ (3 e 4 l i.a./ha) e de Lorsban 10G (2kg i.a./ha).

Para um mercado extremamente exigente, que requeira batatas livres de furos e/ou com boa aparência, os dois tratamentos que, potencialmente, poderiam atender a esta exigência seriam o Granutox $50 \mathrm{G}$, na dosagem de $2 \mathrm{~kg}$ i.a./ha e o Lorsban $10 \mathrm{G}$, na dosagem de $3 \mathrm{~kg}$ i.a./ha.

O mercado, com raras exceções, não é tão exigente. Deste modo, acredita-se que cultivares com tubérculos grandes, como os produzidos pela Trapeira, teriam plena aceitação quando tivessem, no máximo, até 7 furos (enquadrados nas categorias de dano 1, 2 e 3). Assim, na tabela 2, são apresentados os dados cumulativos das percentagens de tubérculos, enquadrados em duas categorias, ou seja, até 7 furos (A) e aqueles com mais de 7 furos (B).

Os tratamentos com Lorsban $10 \mathrm{G}(3 \mathrm{~kg}$ i.a./ha) e Granutox $50 \mathrm{G}$ ( $2 \mathrm{~kg}$ i.a./ha) foram os que propiciaram maior quantidade de tubérculos de batata na categoria cumulativa até 7 furos por tubérculo, diferindo estatisticamente somente da testemunha e do tratamento Lorsban 480 CE (21 i.a./ha), onde se constataram as menores quantidades de tubérculos enquadradas nesta categoria. Lorsban 10G (2kg i.a./ha) e Lorsban 480CE (4 e 31 i.a./ha)

\section{Tabela 2 - Percentagem média de tubérculos de batata enqua- drados nas categorias de dano cumulativo de Dia- brotica speciosa, Pelotas-RS, 1997.}

\begin{tabular}{|c|c|c|c|}
\hline \multirow[b]{2}{*}{ Tratamentos } & \multirow[b]{2}{*}{ Dosagem } & \multicolumn{2}{|c|}{ Categoria de dano $^{1}$} \\
\hline & & A & $\mathrm{B}$ \\
\hline Lorsban $480 \mathrm{CE}$ & $21 \mathrm{i} . \mathrm{a} / \mathrm{ha}$ & $75,0 \mathrm{~b}^{2}$ & $25,0 \mathrm{a}$ \\
\hline Lorsban $480 \mathrm{CE}$ & 3 li.a./ha & $79,0 \mathrm{ab}$ & $21,0 \mathrm{ab}$ \\
\hline Lorsban $480 \mathrm{CE}$ & 4 i i.a./ha & $80,0 \mathrm{ab}$ & $20,0 \mathrm{ab}$ \\
\hline Lorsban $10 \mathrm{G}$ & $2 \mathrm{~kg}$ i.a/ha & $82,5 \mathrm{ab}$ & $17,5 \mathrm{ab}$ \\
\hline Lorsban $10 \mathrm{G}$ & $3 \mathrm{~kg}$ i.a $/ \mathrm{ha}$ & $99,0 \mathrm{a}$ & $1,0 \mathrm{~b}$ \\
\hline Granutox $50 \mathrm{G}$ & $2 \mathrm{~kg}$ i.a/ha & 99,0 a & $1,0 \mathrm{~b}$ \\
\hline Testemunha & - & $70,5 \mathrm{~b}$ & $29,5 \mathrm{a}$ \\
\hline
\end{tabular}

apresentaram-se, nesta categoria de avaliação, como um grupo intermediário, não diferindo estatisticamente da testemunha, bem como, dos melhores tratamentos.

\section{CONCLUSÕES}

Os seguintes tratamentos, em ordem decrescente (ponderando-se o percentual de enquadramento na categoria de dano 1 e na categoria cumulativa de dano até 7 furos), podem ser considerados eficientes para o controle de larvas de Diabrotica speciosa na cultura da batata: Granutox 50G, na dosagem de $2 \mathrm{~kg}$ i.a./ha; Lorsban $10 \mathrm{G}$, na dosagem de 3 e $2 \mathrm{~kg}$ i.a./ha e Lorsban 480CE, na dosagem de 4 e 31 i.a./ha.

\section{REFERÊNCIAS BIBLIOGRÁFICAS}

BAlCABAO, M., MANETTI, P.L., AlvareZ CASTILlo, H.A., et al. Persistencia en el suelo de los inseticidas utilizados en el cultivo de papa. In: CONGRESSO BRASILEIRO DE ENTOMOLOGIA, 16, Salvador-BA, 1997. Resumos... Salvador, SEB/EMBRAPA-CNPMF, 1997, p. 188.

BISOGNIN, D. (Coord.). Recomendações técnicas para o cultivo da batata no Rio Grande do Sul e Santa Catarina. Santa Maria: UFSM/CCR. Departamento de Fitotecnia, 1996, $64 \mathrm{p}$.

BONINE, D.P. Suscetibilidade de cultivares de batata (Solanum tuberosum L.) à Diabrotica speciosa (Germ.) (Coleoptera:Chrysomelidae) e ocorrência de outras pragas subterrâneas. Dissertação (Mestrado em Agronomia) - Curso de Pós-graduação em Fitossanidade, Universidade Federal de Pelotas, 1997

BONINE, D.P., SALLES, L.A.B. Suscetibilidade de cultivares de batata ao dano de larvas de Diabrotica speciosa no tubérculo, em quatro locais do Rio Grande do Sul. In: CONGRESSO BRASILEIRO DE ENTOMOLOGIA, 16., Salvador-BA, 1997. Resumos... Salvador, SEB/EMBRAPA-CNPMF, 1997, p. 320 .

FIOREZE, C., THUROW, S., ROJAHN, P., et al. Diagnóstico das regiões produtoras de batata do Rio Grande do Sul. In: PRIMEIRO SEMINÁRIO DE ATUALIZAÇÃO DA CULTURA DA BATATA. Santa Maria-RS, 1997. Resumos... Santa Maria, UFSM-CCR, 1998. (no prelo).

SANTOS, A.C., FERNANDES, O.D. Eficiência de diferentes formulações de Clorpirifós no controle de larvas de Diabrotica speciosa (Coleoptera: Chrysomelidae) em batata. In: CONGRESSO BRASILEIRO DE ENTOMOLOGIA, 16., Salvador-BA, 1997. Resumos... Salvador, SEB/EMBRAPACNPMF, 1997, p. 163.

Ciência Rural, v. 29, n. 2, 1999. 